\title{
USE OF THE E-PORTFOLIO IN THE EDUCATIONAL PROCESS
}

\author{
Sandra Kučina Softić ${ }^{\text {, }}$ Tona Perišić Pintek ${ }^{2}$, Zvonko Martinović $^{3}$, Zoran Bekić ${ }^{4}$ \\ ${ }^{1-4}$ University of Zagreb University Computing Centre, Croatia
}

\begin{abstract}
E-portfolio is a learning tool that is recognized as valuable in enhancement of the quality of teaching and learning and orientation towards student-centred learning. It can be used for various purposes in education, from storing learners' work, recording achievements, as assessment of and for learning, as a means for monitoring learners' progress, for presentation and marketing purposes or for mobility between educational institutions. E-portfolio has been present for more than a decade and its benefits in education were immediately recognized with predictions for prominent future. But today, it is still being rediscovered, explained and introduced despite some really good examples of use. The University of Zagreb started with the process of e-portfolio implementation in 2008 by establishing the university e-portfolio system and providing support to users. In 2012, this process was fostered with the project "Use of the e-portfolio system in the educational process" in cooperation with the University of Porto, Portugal. The presentation will summarise opportunities of using e-portfolio in higher education with emphasis on the e-portfolio as a learning activity. Also, an overview will be given on the e-portfolio implementation process at the University of Zagreb.
\end{abstract}

\section{What is e-portfolio?}

There are many definitions of a portfolio and it can be used for different purposes. In general it can be said that a portfolio is a collection of artefacts produced by the same person. The most familiar example of portfolios are those of artists with a collection of their work. When talking about a definition of a portfolio in education it is usually defined as a collection of documents which describe learning process. An electronic portfolio uses digital technologies, allowing the portfolio developer to collect and organize portfolio artefacts in various media types (audio, video, graphics, text). An electronic portfolio is also known as webfolio, e-portfolio or digital portfolio. Usually, webfolio is a portfolio in a digital form published on the Internet. E-portfolio is webfolio developed using software which enables basic and additional functionalities. Main actors in higher education are students, teachers and institutions, so eportfolio can be defined upon the type of user as: student e-portfolio, teacher e-portfolio or institution eportfolio. Another way of classification is the one upon the context. Usually there are four types of eportfolios classified in such a way: developmental, assessment, showcase and hybrid.

\section{E-portfolio as a learning activity}

Although e-portfolios can be used for summative assessment their main purpose should be supporting formative assessment for learning. Formative assessment provides students with information on their progress upon which they can take some action. Based on this information they can reflect upon their work, improve it or get confirmation that they are progressing well. If it is done continually during the course students can demonstrate their learning process and not only final results. Students also become used to review their work upon received feedback and to self assess themselves as well. Eportfolio can be a learning activity which enables evaluation of knowledge a student has acquired during the semester/course, and it can be created in a form of a page or a journal. Students develop their web page through which they can demonstrate their knowledge (seminar work, homework, assessment test). Teachers can then give feedback on their work and it is possible that feedback is given by students as well. This activity can be individual, but it can also be a team work. The journal developed in the e-portfolio can be used for the discussion purposes and reflection on the learning process. Students have a possibility to give their opinion and discuss about the course content, defined learning outcomes, learning materials, acquired knowledge, other materials and texts related to the course subject, on their personal development (i.e. difficulties which they have encountered in learning and accessing learning materials...) and so on. Journals can be in freestyle and entries can be reviewed and commented chronologically. 
By providing feedback to each student during the course, teachers are giving students a possibility to personalize their learning process and to be in charge of it. Information gained in formative assessment through learning activities can help teachers get better picture of each student's progress, to adapt the teaching and meet the learner's needs.

\section{Implementation of the e-portfolio in the educational process}

A teacher can decide to use e-portfolio in the education, but decision is usually not enough. They also need a tool, support (technical and pedagogical) and students who will want to use it. Teachers also have to be aware and prepared that implementation of new tools and new methods of teaching require significant amount of time and effort in the beginning. Better preconditions for the e-portfolio use have teachers who have centralised e-portfolio installation and teacher's trainings programmes at institutions, so they can focus on methodology and reasons of the e-portfolio implementation. But that is a small number; the majority of teachers are often left to themselves to think about how to engage in something new. Institutions often think that purchasing technology is enough and they forget support and training which should be provided to teachers and all the academic staff and we shouldn't forget students as well. They need support and training as well.

Students can easily lose interest if they find a tool complicated to use while support and some training is not available. It is very important that students see purpose of using e-portfolio activity in the course because if it is forced upon them and they don't find it interesting and applicable, the cause of the use is lost. Not all students will find a personal benefit to use something new proposed by a teacher and majority will need a motivation. They can be motivated in a way that it is obligatory (i.e. to finish the course) or that they see a benefit in it. It is desirable to introduce it as a possibility which will bring series of benefits. Along with that, clear instructions at the beginning of the course on how to use it, what is its purpose in the course, how it is related to the learning outcomes or that it can be of help in their learning or research are also very important.

Unfortunately, today, lots of students still rely on the traditional model of learning in which they are passive participants and find reflective learning hard because it requires them to engage and the high level of commitment and effort. Although it can be hard for teachers and students in the beginning, usually achieved results justify the effort and bring the smiles to the faces of the both.

Today, two things make e-portfolio the one of the most interesting fields of development in the education and training process. The first is the prefix "e" which makes a portfolio digital and enables transformation of passive information to dynamic, flexible and growing, which can be shared, developed, put in the different contexts, searched or looked at from different perspectives. The second issue is shift to the lifelong learning which place students in the centre of the learning process. The ability of active learning with use of e-learning technologies has become an element of general literacy in any knowledge-based society. Students should and need to take the control over their educational process, continually self-assessing and reflecting on their learning path and achievements, deciding which further steps to make and which knowledge they need to achieve it. So, e-portfolio can be used as a good catalyst to enhance that.

\section{E-portfolio implementation process at the University of Zagreb}

The University of Zagreb is a traditional and research oriented university. Implementation of the Bologna process and reform of higher education brought new challenges in maintaining traditional values of university education and synergizing them with a new kind of knowledge and skills. Implementation of e-learning technologies with the aim to enhance university education and to achieve some of Bologna principles started in 2007 with the adoption of the university e-learning strategy.

The E-learning Centre at the University Computing Centre SRCE at the University of Zagreb was established as the central point at the university level which provides assistance in the implementation of e-learning. One of the tasks of the E-learning Centre became e-portfolio implementation defined as an activity which should be realised within the University of Zagreb E-learning Strategy.

E-portfolio as an e-learning tool is relatively new at the University of Zagreb. There have been some attempts for its use in education by individuals but to the broader audience it was introduced in 2008. Within the E-learning Strategy, e-portfolio was seen as the system for students' support during their 
education enabling them to record their achievements and experience obtained during studies, but also as a way to present their qualifications and competencies to future employers in pursuing adequate job and starting of professional career. Faced with challenge of the e-portfolio implementation, the Elearning Centre at SRCE decided to find the tool which is reliable, accessible and will be free of charge to users. Decision fell upon the e-portfolio system Mahara as the e-portfolio tool which has the possibility to stand alone but also to be connected with a LMS, to provide multiple pages and can be easily administered especially regarding the access. After the installation, the e-portfolio system was connected with the university LMS (based on Moodle) using single sign-on and thus creating virtual environment easily accessible to users. Along with the accessibility of e-portfolio system, the E-learning Centre at SRCE organized training and support to users. Organized support can be decisive for users and knowing that it exist and is available makes users less reluctant to try something new. E-portfolio was introduced to the academic community at the events, disseminated through web pages and the network of the e-learning representatives at schools of the University of Zagreb. But majority of teachers didn't find it appealing, because as faced with the emergence of digital tools it was not easy to distinguish and decide which one to use and to implement in the educational process.

\section{Project Use of the e-portfolio system in the educational process}

In 2012 the E-learning Centre started with the project Use of the e-portfolio system in the educational process in cooperation with the University of Porto, Portugal. This one year project had a goal to foster the e-portfolio implementation in the educational process and to train teachers on the e-portfolio and its use as a learning activity, to enable them to see it as a way to enhance their teaching methods and to adapt education to the needs of today's society.

Lectures and workshops were held in the project with the aim to introduce e-portfolio and its possibilities for use in the educational process to teachers. Within these lectures and workshops teachers were also able to hear and see examples of the good practice of e-portfolio use as a learning activity from colleagues at the University of Zagreb and the University of Porto. This was also a good opportunity for a discussion and acquiring of new ideas about how to implement e-portfolio in the teaching and getting the way to engage students to actively participate in the course and at the same time to monitor their learning process. The project has started in March 2012 and lasted one year. In the project, besides lectures and workshops, web pages on Croatian and English were established as a way of dissemination of information about the project and project activities but also as a repository of materials and recordings of lectures. One of the results of the project is the Manual on the use of eportfolio as a learning activity for teachers which have been published in Croatian and under the Creative Commons licence and is available on the project web pages. The plan is to translate it into English so that teachers worldwide can use it.

The project attracted mostly teachers who have already started using new methodologies in the teaching process and who are known as the "early adopters" and "early majority". Reliable support and recognition which the E-learning Centre at SRCE has gained during years has also helped as teachers were more open to listen and learn. The number of teachers using e-portfolio has been slowly increasing. We can conclude that on the received feedback from teachers who have started using it as a learning activity, increased number of questions to the E-learning Centre related to the use of the eportfolio and number of groups (related to the courses) on the e-portfolio system. Questions related to the e-portfolio have been included in the annual survey on e-learning at the University of Zagreb. The E-learning Centre will continue with further promotion of e-portfolio and it possibilities for use as learning activity and will provide reliable and sustainable support to users in future.

\section{Conclusion}

The issue is how to find an appropriate way to introduce and to use technology and how to manage the process of change in the university teaching and learning. E-portfolio demonstrated a great potential in the educational process but in order to implement e-portfolio, teachers, students and institutions need to have a clear idea what it is, what its purpose is and why it should be used in education. Today's educators are not properly trained to embed ICT in their pedagogical practices. They have to find its benefit in the development of the learning process. In order to do that, institutions should spend time to introduce it to the academic community, to involve all interested stakeholders in the discussions on its 
effectiveness in the educational process and to focus primarily on the necessary changes in the teaching and learning process which cannot be delayed any longer.

\section{References:}

1. JISC (2008). Effective Practice with e-Portfolios - Supporting $21^{\text {st }}$ century learning. Retrieved on December 17, 2012.

http://www.jisc.ac.uk/media/documents/publications/effectivepracticeeportfolios.pdf

2. Martins, I., Correia, T. and Soeiro A. (2008). Digital Portfolios in University of Porto: defining goals. Retrieved on December 17, 2012, http://repositorio-aberto.up.pt/bitstream/10216/56249/2/903.pdf

3. Project "Use of the e-portfolio system in the educational project", University of Zagreb University Computing Centre, web pages http://www.srce.unizg.hr/homepage/products-services/education/elearning-centre/international-relations/use-of-e-portfolio-system-in-educational-process/ 